\title{
Fingerprints of a riming event on cloud radar Doppler spectra: observations and modeling
}

\author{
Heike Kalesse $^{1, \mathrm{a}}$, Wanda Szyrmer ${ }^{1}$, Stefan Kneifel ${ }^{1, \mathrm{~b}}$, Pavlos Kollias $^{1, \mathrm{c}}$, and Edward Luke ${ }^{2}$ \\ ${ }^{1}$ McGill University Montreal, Montréal, QC, Canada \\ ${ }^{2}$ Brookhaven National Laboratory, Upton, NY, USA \\ ${ }^{a}$ now at: Leibniz-Institute for Tropospheric Research, Leipzig, Germany \\ ${ }^{b}$ now at: University of Cologne, Cologne, Germany \\ ${ }^{\mathrm{c}}$ now at: Stony Brook University, Stony Brook, NY, USA \\ Correspondence to: Heike Kalesse (kalesse@tropos.de)
}

Received: 23 July 2015 - Published in Atmos. Chem. Phys. Discuss.: 22 October 2015

Revised: 11 February 2016 - Accepted: 16 February 2016 - Published: 9 March 2016

\begin{abstract}
Radar Doppler spectra measurements are exploited to study a riming event when precipitating ice from a seeder cloud sediment through a supercooled liquid water (SLW) layer. The focus is on the "golden sample" case study for this type of analysis based on observations collected during the deployment of the Atmospheric Radiation Measurement Program's (ARM) mobile facility AMF2 at Hyytiälä, Finland, during the Biogenic Aerosols - Effects on Clouds and Climate (BAECC) field campaign. The presented analysis of the height evolution of the radar Doppler spectra is a state-of-the-art retrieval with profiling cloud radars in SLW layers beyond the traditional use of spectral moments. Dynamical effects are considered by following the particle population evolution along slanted tracks that are caused by horizontal advection of the cloud under wind shear conditions. In the SLW layer, the identified liquid peak is used as an air motion tracer to correct the Doppler spectra for vertical air motion and the ice peak is used to study the radar profiles of rimed particles. A 1-D steady-state bin microphysical model is constrained using the SLW and air motion profiles and cloud top radar observations. The observed radar moment profiles of the rimed snow can be simulated reasonably well by the model, but not without making several assumptions about the ice particle concentration and the relative role of deposition and aggregation. This suggests that in situ observations of key ice properties are needed to complement the profiling radar observations before process-oriented studies can effectively evaluate ice microphysical parameterizations.
\end{abstract}

\section{Introduction}

Mixed-phase clouds are ubiquitous, long-lived, and cover extended areas (e.g., Shupe et al., 2008; Zhang et al., 2010; Kanitz et al., 2011). However, the factors governing the formation, maintenance, and dissipation of mixed-phase clouds are poorly understood and consequently not well represented in weather and climate models (Cantrell and Heymsfield, 2005; Lebo et al., 2008; Barrett et al., 2010). The complex interaction between atmospheric vertical motions, aerosol particles, water vapor, liquid water, and ice determine the radiative and microphysical properties of mixed-phase clouds to a large extent (Gregory and Morris, 1996). Microphysical processes such as water vapor diffusion, collision, coalescence, aggregation, and riming are controlled by the variable mass ratio between liquid water and ice (Pruppacher and Klett, 1997). The ongoing increase in the temporal and spatial resolution of numerical models suggests that cloud microphysical processes will be modeled in ever more detail in the coming decades (Klein et al., 2013). In that context, the development of process-level understanding has been found to be a key for success in addressing the complicated nature of mixed-phase clouds and improving their representation in numerical models (Morrison et al., 2012).

Mixed-phase clouds pose a serious observational challenge due to the difficulty of identifying the presence of supercooled liquid water (SLW) layers embedded in cloud regions dominated by ice (Luke et al., 2010). Existing mixedphase cloud classifications are highly uncertain and lead to 
a misrepresentation of these clouds in models (Illingworth et al., 2007). Moving beyond the detection of SLW layers and into process-oriented studies (e.g., riming) requires synergetic observations with cloud Doppler radars and microwave radiometers (MWRs) in combination with backscatter and Doppler lidars (e.g., Verlinde et al., 2013). As highlighted in Kollias et al. (2007a) spectral Doppler information is expected to be one of the main tools for future observational studies on cloud microphysics (see Sect. 2.3 for details).

Here, a $35 \mathrm{GHz}$ cloud Doppler radar is used in synergy with a microwave radiometer to identify and characterize a SLW layer within a mixed-phase cloud and its effect on the cloud microphysics. The recorded radar Doppler spectra are bimodal, thus comprised of a liquid and an ice spectral peak (e.g., Shupe et al., 2004). As in Shupe et al. (2004), the vertical air motion within the SLW layer is retrieved from cloud radar Doppler spectra. The liquid peak radar reflectivity is used to retrieve the SLW profile while the spectral peak associated with typical ice and snow terminal velocities is used to detect and follow the evolution of riming. The temporal (height) evolution of the radar Doppler spectrum is analyzed along slanted fall streaks from cloud top to cloud base to optimally follow the particles' history in order to gain insight into microphysical processes occurring in different layers of the mixed-phase cloud (Marshall, 1953; Hogan and Kew, 2005).

This study illustrates the objective steps in identifying the impact of a microphysical process (riming) on radar observations (fingerprints) and the steps required to analyze a multisensor data set containing radar Doppler spectra. While the implementation of the aforementioned retrieval and analysis technique is valuable, this is not purely a retrieval effort. The main question this study aims to address is to what extent such process-oriented studies (i.e., fingerprinting studies) can be used to evaluate existing riming efficiency parameterizations (e.g., Hall, 1980; Cober and List, 1993; Lohmann, 2004). To accomplish this, a 1-D steady-state bin microphysics model is used to model the riming event. Restating that this is not a retrieval contribution, the goal is not to reproduce the evolution of riming ice spectra peak moments but rather to assess whether the observations can sufficiently constrain other parameters and factors that can affect the model output.

The structure of the paper is as follows. The data, instrumentation, and background of radar Doppler spectra processing are introduced in Sect. 2. Section 3 gives a detailed analysis of the snowfall case study including a description of the synoptic situation (Sect. 3.1), the in situ observations (Sect. 3.2), the cloud radar and MWR observations as well as the fall streak tracking technique, and the evolution of the cloud radar Doppler spectrum (Sect. 3.3). In Sect. 3.4 the 1-D microphysical bin model used to reproduce the rimed-mode radar moments is described and a comparison of observations with model results is discussed. A summary and conclusions are provided in Sect. 4.

\section{Data, instrumentation, and Doppler spectra processing}

\subsection{BAECC field campaign overview}

From 1 February to 12 September 2014 the Biogenic Aerosols - Effects on Clouds and Climate (BAECC) field experiment (Petäjä et al., 2016) - a joint project of the University of Helsinki, the Finnish Meteorological Institute, and the US Department of Energy (DOE) Atmospheric Radiation measurement (ARM) program - took place in the boreal forest of southern Finland. For that purpose, extensive remote sensing and in situ instrumentation was installed at the Station for Measuring Ecosystem-Atmosphere Relations (SMEAR II, Hari and Kulmala, 2005) at the Hyytiälä field station of the University of Helsinki located at $61^{\circ} 50^{\prime} 37.114^{\prime \prime} \mathrm{N}$ and $24^{\circ} 17^{\prime} 15.709^{\prime \prime} \mathrm{E}, 150 \mathrm{~m}$ above sea level. Within that frame, an intensive observation period focusing on winter precipitation (BAECC-Snowfall Experiment (SNEX)) organized in collaboration with the National Aeronautics and Space Administration (NASA) Global Precipitation Measurement (GPM) ground validation program and Colorado State University was conducted from 1 February to 30 April 2014.

\subsection{Instrumentation}

The second ARM Mobile Facility (AMF2), consisting of an extensive suite of remote sensing instruments such as a Ka-band ARM Zenith-pointing Radar (KAZR), a W-, Ka-, and X-band Scanning ARM Cloud Radar (Kollias et al., 2014), a micropulse lidar (MPL), a High Spectral Resolution Lidar (HSRL), and a two-channel MWR (Cadeddu et al., 2013) was deployed at the observation site. The lidars are used for detection of cloud base height and cloud particle phase, the radars for characterization of cloud and precipitation microphysics, and the MWR for determination of column-integrated amounts of liquid water and water vapor. For this study, data from the Ka-band ARM Zenith-pointing Radar (KAZR) operating at $35 \mathrm{GHz}$, as well as the MWR are used.

Ground-based in situ sensors included a Particle Imaging Package (PIP), which is a new version of the Snow Video Imager (Newman et al., 2009). Pluvio weighing gauges were employed to measure precipitation rate and snowfall accumulation. Pluvios were also used in combination with the PIP for determination of total particle concentration, particle size distribution (PSD), and particle terminal fall velocities from which fall velocity-size relations were derived at high temporal resolution.

For a detailed description of the measurement site setup as well as the in situ and remote sensing instrumentation and data processing please refer to Kneifel et al. (2015). In addition to the mentioned instrumentation, radiosondes were 
launched four times daily for profiling of the atmospheric state variables.

\subsection{Doppler spectra processing}

The mean Doppler velocity from profiling radars has been used in past studies to detect and study riming. Initially, Weiss and Hobbs (1975) distinguished ice crystal growth by riming from growth by water vapor deposition by observing the different rates of change of mean Doppler velocity with height. Mosimann (1995) used a vertically pointing Doppler radar in combination with snow crystal in situ measurements to quantitatively determine an index of the degree of riming in stratiform precipitation, a technique which has been used in further studies (e.g., Borys et al., 2003; Baschek et al., 2004).

Today, advancements in signal processing and radar technology and decreasing storage costs have enabled the routine recording of the full radar Doppler spectrum. The radar Doppler spectrum often contains unique signatures that can be used to retrieve cloud microphysics and dynamics (Kollias et al., 2007b). In particular, the presence of liquid cloud droplets in the radar sampling volume allows use of the Doppler spectra peak of the liquid particles to derive the mean vertical air motion of the sampling volume. This approach is based on the assumption that the terminal velocity of small cloud droplets is negligible compared to typical vertical air motions in clouds (Kollias et al., 2001). Thus, the location of the peak caused by liquid droplets in the Doppler spectrum can act as a tracer for vertical air motion.

This implies that in SLW layers also containing ice particles, if the liquid spectral peak does not significantly overlap the ice peak in velocity, then the cloud dynamics (vertical air motion and eddy dissipation rate) can be retrieved (Kollias et al., 2001; Shupe et al., 2004). The potential of using multimodal cloud radar Doppler spectra for characterizing the liquid- and ice-phase components in mixed-phase clouds has been previously demonstrated (e.g., Shupe et al., 2004; Luke et al., 2010; Luke and Kollias, 2013; Rambukkange et al., 2011; Verlinde et al., 2013; Yu et al., 2014).

Here, in addition to the objective detection and analysis of the SLW spectral peaks, the temporal evolution of the radar Doppler spectrum is analyzed along slanted fall streaks from cloud top to cloud base to gain insight into microphysical processes occurring in different layers in mixedphase clouds. As already highlighted in Marshall (1953), this is necessary in situations when vertical wind shear is observed. Under these conditions, following the particle evolution along straight vertical paths is not suitable for detailed fingerprinting studies. To track radar moments in cirrus, this technique has been refined in Hogan and Kew (2005). Similar to their approach, we do not simply follow the fall streaks in the observations but compare them with simulated fall streaks by using the horizontal wind profile and Doppler fall velocity. In this way we can ensure consistency between the expected fall streak shape, which is solely based on dynamics and particles' fall velocity, and the observations. This approach helps to avoid a subjective and potentially false identification of a fall streak in the observations that might be caused, e.g., by different generating processes and levels or directional wind shear that would hamper the derivation of particle history along the fall streak. To our knowledge, this is the first study in which the evolution of the full Doppler spectrum along slanted fall streak paths is analyzed.

Finally, the SLW radar reflectivity is extracted from the SLW spectral peak and used to derive the profile of SLW content within the SLW layer while the ice rimed spectral peak is used to derive the radar observables of the rimed particles.

\section{Case study analysis}

\subsection{Synoptic situation in Hyytiälä on 21 February 2014}

On 21 February 2014 a low-pressure system situated between Iceland and the British Isles influenced the weather in most parts of Europe. Several surface fronts associated with the weather system moved to the east/northeast. The most prominent one was a partially occluded front that crossed western Europe and reached the stage of a fully developed occlusion further east. Due to increased vertical mixing, it had the characteristics of a warm occlusion near the surface with rising temperatures behind the passage of the front. The advection of warm air is indicated by a veering vertical wind profile in the radio sounding launched at 23.2 UTC as shown in Fig. 1. With warm air sliding over cold air, the first clouds associated with this system were found at higher levels (around $8 \mathrm{~km}$ ).

Prior to the arrival of the warm occlusion in Hyytiälä, multiple cloud layers were present which are obvious in the radiosonde launched at 23.33 UTC. The cloud base of the frontal system was continuously lowering with the approaching warm occlusion. Also, the reflectivity of the cloud as observed by the $35 \mathrm{GHz}$ vertically pointing cloud radar KAZR (cf. Fig. 2) showed tilted fall streak features above $3.5 \mathrm{~km}$ altitude, indicating vertical wind shear consistent with the radio sounding profile of horizontal wind. The temperature profile shows two inversion layers, a boundary layer inversion at $0.5-0.8 \mathrm{~km}$ at which a shallow low-level cloud had formed and a second one at $2.8-3 \mathrm{~km}$ where a mid-level cloud had formed as illustrated in Fig. 3. Cloud top temperatures of the warm occlusion front and the mid-level cloud were $-50^{\circ} \mathrm{C}$ (at $8 \mathrm{~km}$ ) and $-12^{\circ} \mathrm{C}($ at $3.4 \mathrm{~km}$ ), while the surface temperature was $-3^{\circ} \mathrm{C}$, respectively. The ambient relative humidity profile shows layers of saturated/subsaturated conditions associated with the two distinct cloud layers extending from $2.3 \mathrm{~km}$ and higher as well as from 0.2 to $0.9 \mathrm{~km}$. Subsaturated conditions leading to sublimation prevailed between 0.8 and $2.3 \mathrm{~km}$ as well as below $0.2 \mathrm{~km}$. Thus, snowfall associated with the onset of the frontal sys- 

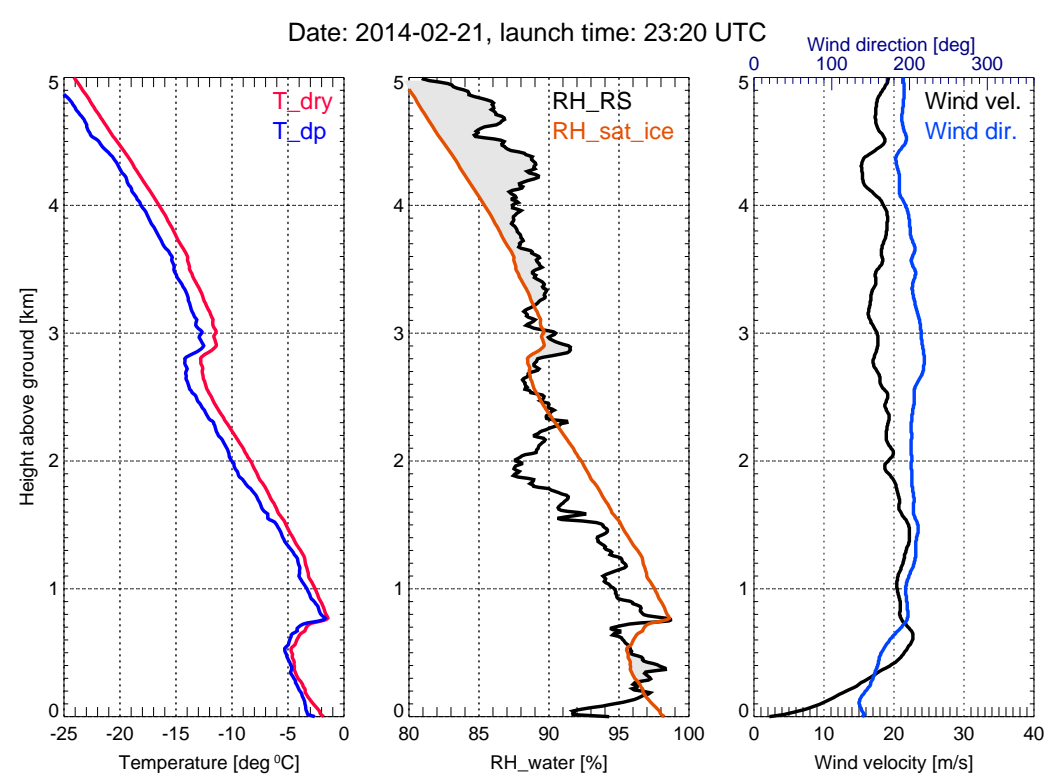

Figure 1. Vertical profiles of temperature (blue, left) and dew point temperature (red, left), relative humidity (middle, black), as well as horizontal wind speed (right, black) and wind direction (right, blue) from a radiosonde launched at 23:20 UTC (23.33 UTC) on 21 February 2014 in Hyytiälä. The red line in the middle panel refers to the humidity at which the air is saturated with respect to ice; i.e., if the relative humidity is to the right of the red line, the air is supersaturated ice (grey shading).

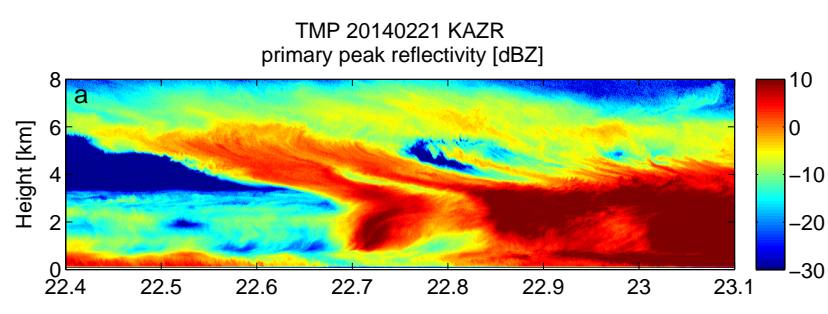

tem (22.7-22.8 UTC) experienced sublimation before reaching the ground.

\subsection{In situ observations}

During the period of interest when the snow front moved in (22.7-22.8 UTC), in situ observations showed low snowfall rates below $\left(0.3 \mathrm{~mm} \mathrm{~h}^{-1}\right)$ and low total ice particle concentrations $\left(<100 \mathrm{~m}^{-3}\right)$. PIP images were often out of focus; however, the structure of several individual ice particles was identified: in addition to small and large oriented dendrites, fast-falling roundish particles with high density - an indication of riming - were observed. In the PIP 22 min time integration interval 22.52-22.88 UTC, areaequivalent maximum observed diameters were less than $1.5 \mathrm{~mm}$ (D. Moisseev, personal communication, 2015). Afterwards (PIP integration time interval 22.88-23.06 UTC), the maximum particle size increased to $3 \mathrm{~mm}$ and snowfall rate was still low but doubled to $0.6 \mathrm{~mm} \mathrm{~h}^{-1}$. Later on (after 23.06 UTC) heavy snowfall of large low-density aggregates was observed with the ground-based instruments and multi-frequency radar measurements as discussed in Kneifel et al. (2015). During the time of interest of this study, the

Figure 2. KAZR-observed primary Doppler spectrum peak moments on 21 February 2014 in Hyytiälä. Panel (a) shows reflectivity (dBZ), (b) mean Doppler velocity $\left(\mathrm{m} \mathrm{s}^{-1}\right.$ ), and (c) spectrum width of the primary Doppler spectrum peak $\left(\mathrm{m} \mathrm{s}^{-1}\right)$. Negative Doppler velocities indicate downward motion. $\mathrm{X}-\mathrm{SACR}$ was not operated in vertically pointing mode.

\subsection{KAZR and MWR observations}

In Fig. 2 the time-height plots of the first three moments (effective radar reflectivity factor $\mathrm{Ze}$, subsequently called reflectivity; mean Doppler velocity $V_{\mathrm{d}}$, and spectral width $\left.(\sigma)\right)$ of 


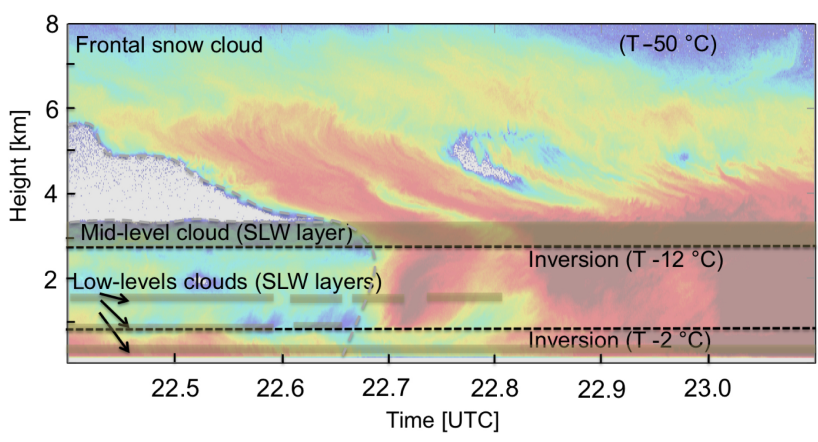

Figure 3. A schematic diagram of the cloud layers present in Hyytiälä on 21 February 2014. Sketch is overlying the KAZR reflectivity.

the primary peak of the KAZR Doppler spectrum are shown. The primary peak is defined to be the noise-separated peak containing the bin with maximum power spectral density (cf. Fig. 4; Kollias et al., 2007b). This is the peak used in the standard ARM radar moments data products. The ARM MicroARSCL data product (Kollias et al., 2007b) extends the reported moments to skewness and kurtosis for both the primary peak and an additional noise-separated secondary peak, if one exists. The peak power densities and modal velocities of up to two local maxima occurring within the primary peak are also reported. Mean and maximum spectral noise power are determined using the technique described in Hildebrand and Sekhon (1974). If only one hydrometeor population is present in the radar volume (cf. Fig. 4a), the radar Doppler spectrum is usually characterized by a single peak above noise floor, which is controlled by the width of the PSD and sub-volume turbulence. In cases with more than one hydrometeor class in the radar volume (e.g, liquid droplets and snow) it is possible to have sufficient fall velocity separation between the two hydrometeor classes so that the radar Doppler spectra is bimodal. As mentioned in Luke and Kollias (2013), strongly multimodal situations can be considered to be "golden" samples as they make it easy to separate the contributions of the individual hydrometeor populations to the total radar return. Here, we classify all peaks which are separated by the mean noise floor into three categories (liquid droplets, freshly generated ice, and (rimed) snow). Peaks are grouped into these classes according to their mean Doppler velocity and spectrum width. However, in many observations, the terminal fall velocity difference between two different particle size distributions is not large enough to produce individual peaks separated by the mean noise floor. Instead, broad merged peaks consisting of the contribution of two or more PSDs occur (cf. Fig. 4d). This is also the reason why only a short time period is analyzed in this study; synoptic situations in which ice particles from a "seeder" cloud above are falling through a SLW layer where they experience riming occurred at least half a dozen times during the BAECC-

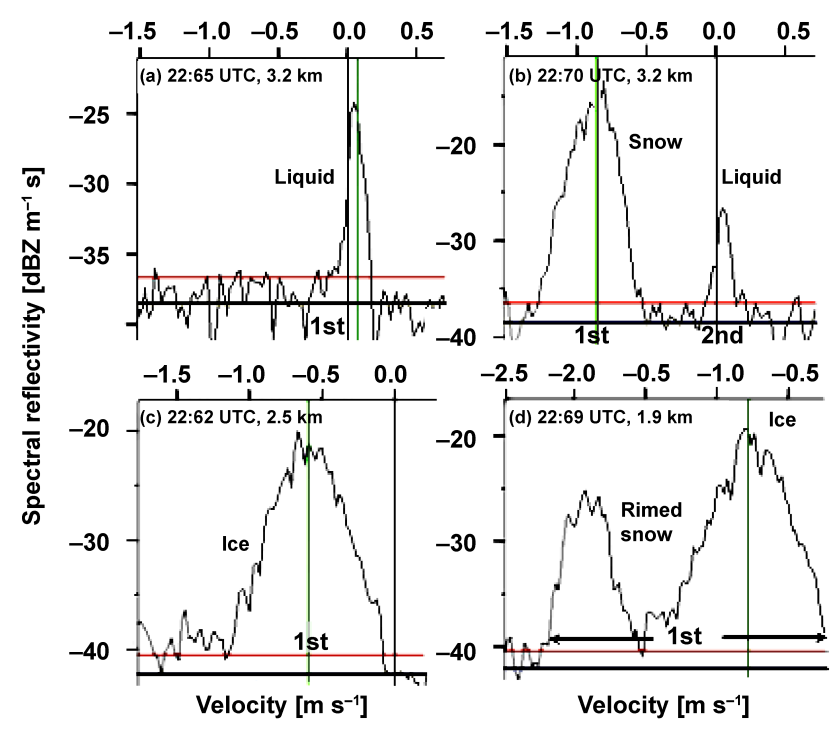

Figure 4. Examples of KAZR Doppler spectra at different times and heights. Notice the different $x$ and $y$ scales. Maximum and mean noise floor determined according to Hildebrand and Sekhon (1974) are indicated by grey and black horizontal lines, respectively. The primary peak is labeled as 1 st, the secondary peak as 2 nd. The mean Doppler velocity of primary peak is shown by the vertical grey line. The plots are created with the Doppler Spectrum Visualizer, a visualization toolkit which is publicly available at http://www.gim.bnl.gov/armclouds/specvis_java_toolkit/.

SNEX period but unfortunately, for all other events, only merged peaks were observed in the KAZR Doppler spectra.

An objective way to distinguish spherical supercooled liquid droplets from freshly generated nonspherical ice would be the use of spectral linear depolarization ratio (LDR). Unfortunately though, no KAZR cross-polarization channel data were gathered during BAECC-SNEX and thus no LDR could be determined. However, microphysical modeling sensitivity tests (not shown) showed that unrealistically high ice particle number concentrations - on the order of a few hundreds to a few thousands per liter for ice particle sizes of a few hundred microns - would be required to produce a peak of about -20 to $-15 \mathrm{dBZ}$ at $0.15 \mathrm{~m} \mathrm{~s}^{-1}$. For this regime of sizes, the observed ice particle number concentration reported in the literature is below 10 per liter (e.g., Zhang et al., 2014; Lloyd et al., 2015). We can thus assume that power spectrum peaks at small velocities are due to liquid droplets and not ice particles.

In this study, the focus is on the period when the upper level snow band moves in, roughly from 22.4 UTC when first detected by the KAZR to the end of the first snow shower at around 22.77 UTC. In the KAZR reflectivity field (cf. Fig. 2a) the onset of snowfall is clearly visible by the high $\mathrm{Ze}(>-5 \mathrm{dBZ})$ area extending from a fall streak feature at a height of $8 \mathrm{~km}$ downwards. The Ze structure is strongly tilted above $3.5 \mathrm{~km}$ due to horizontal wind shear. The decrease in 
Ze at 22.7-22.77 UTC below $1 \mathrm{~km}$ can likely be attributed to sublimation in an ice-subsaturated layer (cf. humidity profile in Fig. 1).

Before the arrival of the snow band in Hyytiälä, a liquidtopped mixed-phase cloud with cloud top at $3.4 \mathrm{~km}$ is observed (see Fig. 3). Its roughly $500 \mathrm{~m}$ thick SLW layer can clearly be distinguished by mean Doppler velocities of around $0.0 \mathrm{~m} \mathrm{~s}^{-1}$ in Fig. $2 \mathrm{~b}$, as well as very narrow spectrum width values below $0.08 \mathrm{~m} \mathrm{~s}^{-1}$ and low reflectivity values (Ze $<-15 \mathrm{dBZ})$. A typical KAZR Doppler spectrum example within this liquid layer is shown in Fig. 4a. Within this SLW layer new ice formation took place at about $-12{ }^{\circ} \mathrm{C}$; subsequently, the ice sedimented and grew in size as reflected by a gradual increase of Ze (22.4-22.69 UTC) between 2.9 and $0.9 \mathrm{~km}$, as well as an increase of $V_{\mathrm{d}}$ and $\sigma$. A Doppler spectrum example of this freshly generated ice mode is shown in Fig. 4c. The rapid increase of $\mathrm{Ze}$ below $0.9 \mathrm{~km}$ prior to the snowfall indicates ice particle riming which is confirmed by the ground-based in situ observations of rimed ice crystals during that time period. The riming most likely occurred in another SLW layer at the lower inversion at $0.7-0.9 \mathrm{~km}$, characterized by mostly non-noise-floorseparated liquid peaks in the Doppler spectra (not shown). Strong surface turbulence below $0.8 \mathrm{~km}$ is obvious in highly variable $V_{\mathrm{d}}$ and high $\sigma$. The strong turbulence in the surface layer led to a broadening of the Doppler spectra peaks which resulted in broad merged peaks (not separated by the noise floor) and thus hampered the application of our microphysical retrievals for that SLW layer.

When the snow band starts falling through the SLW layer, the primary peak moments are not sufficient to capture the radar view of the microphysics. The coincidence of liquid and ice particle size distributions within the KAZR sampling volume leads to multimodal KAZR radar Doppler spectra due to the terminal fall velocity difference between the liquid droplets and the falling snow (Fig. 4b). As obvious in Fig. $4 \mathrm{~b}$, the snow falling through the SLW layer has a higher dynamic range than the liquid mode and is thus classified as the principle peak, leading to a sudden change of $V_{\mathrm{d}}$ values in Fig. 2b after 22.69 UTC and below $3.4 \mathrm{~km}$. Similarly, the sudden high values of $\sigma$ at 22.68-22.7 UTC and below $2 \mathrm{~km}$ can be explained by a merged peak of the freshly generated ice and the snow which are no longer separated by the mean noise floor, as illustrated in Fig. 4d. The strong increase of $V_{\mathrm{d}}$ (on the order of $0.5 \mathrm{~m} \mathrm{~s}^{-1}$, cf. Fig. 2b) within the SLW layer indicates riming of particles, as also seen in the in situ measurements (cf. Sect. 3.2).

Observations supporting the presence of riming when the snow fall streak intercepts the SLW layer are provided in the temporal evolution of the MWR liquid water path (LWP) shown in Fig. 5b. While the LWP varies between 320 and $400 \mathrm{~g} \mathrm{~m}^{-2}$ before 22.69 UTC when only the liquid-topped mixed-phase cloud is present, it rapidly decreases from 400 to $250 \mathrm{~g} \mathrm{~m}^{-2}$ within $3 \mathrm{~min}$ (22.69-22.74 UTC). The observed reduction in the LWP can partly be attributed to the capturing
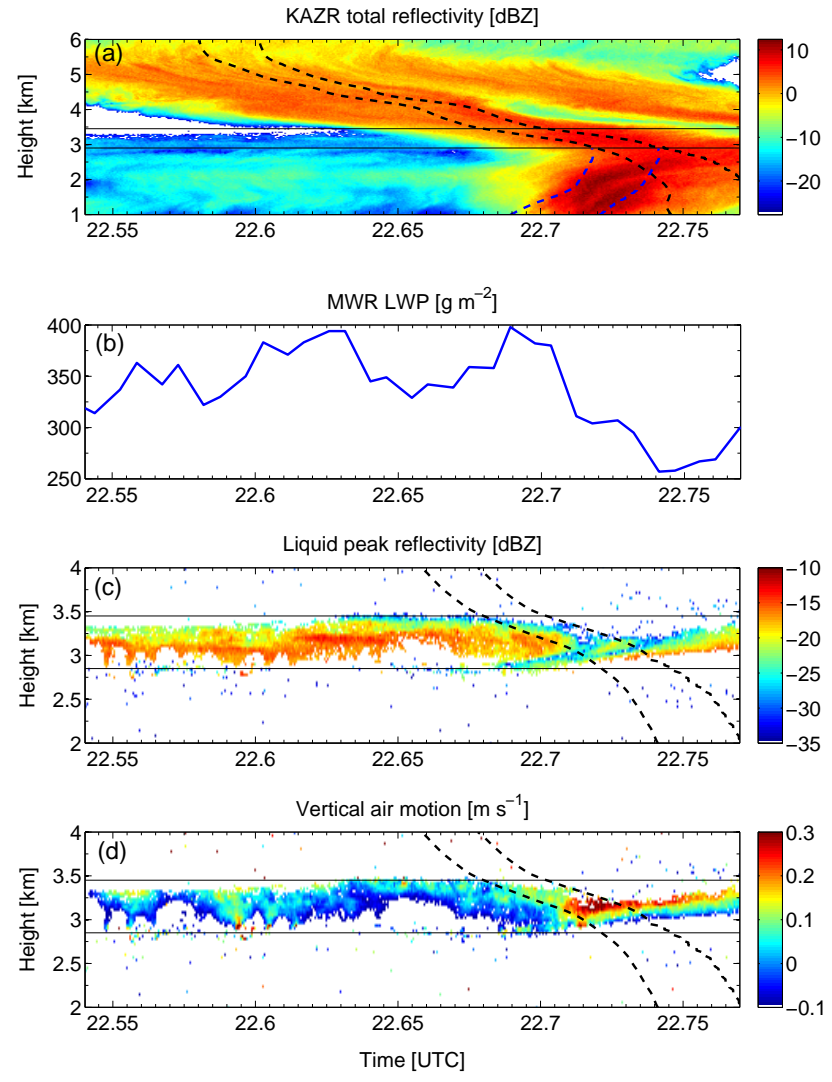

Figure 5. Zoomed view (2-4 km, 22.54-22.77 UTC) of the snow front on 21 February 2014. Panel (a) shows KAZR total reflectivity, (b) microwave radiometer (MWR) liquid water path (LWP), (c) reflectivity of the liquid peak, (d) mean Doppler velocity of the liquid peak used as vertical air motion tracer. The dotted lines depict individual fall streaks starting at different generating levels $z_{\text {gen }}\left(z_{\text {gen }}=6 \mathrm{~km}\right.$ (black), $z_{\text {gen }}=2.9 \mathrm{~km}$ (blue)). All subsequent averaged profiles refer to the area between the two black fall streaks.

of SLW droplets by the falling snowflakes, leading to rimed particles with high density and fast fall velocities.

It should be noted that the vertically integrated value of LWP cannot be entirely attributed to the layer of SLW at $2.9-3.4 \mathrm{~km}$. Unfortunately, the entire vertical distribution of SLW cannot be reconstructed because the lidar signal was already extinguished by a thin SLW layer at $0.2-0.4 \mathrm{~km}$. However, two more thin SLW layers were detected by KAZR Doppler spectrum analysis at $0.8-0.9$ and $1.5-1.7 \mathrm{~km}$ (see Fig. 3). These layers however were intermittent and coincide in time with the periods of the highest values of LWP around 22.6-22.65 and 22.7 UTC. When these intermittent layers were observed, the LWP increased by $60-80 \mathrm{~g} \mathrm{~m}^{-2}$; we use this values as the estimate of their combined contribution to the total LWP. The SLW layer that had formed at the lower temperature inversion at $0.8 \mathrm{~km}$ is a remnant signature of the long-lived thin mixed-phase cloud with cloud top at just below $0.9 \mathrm{~km}$ that was present since before 14 UTC. 

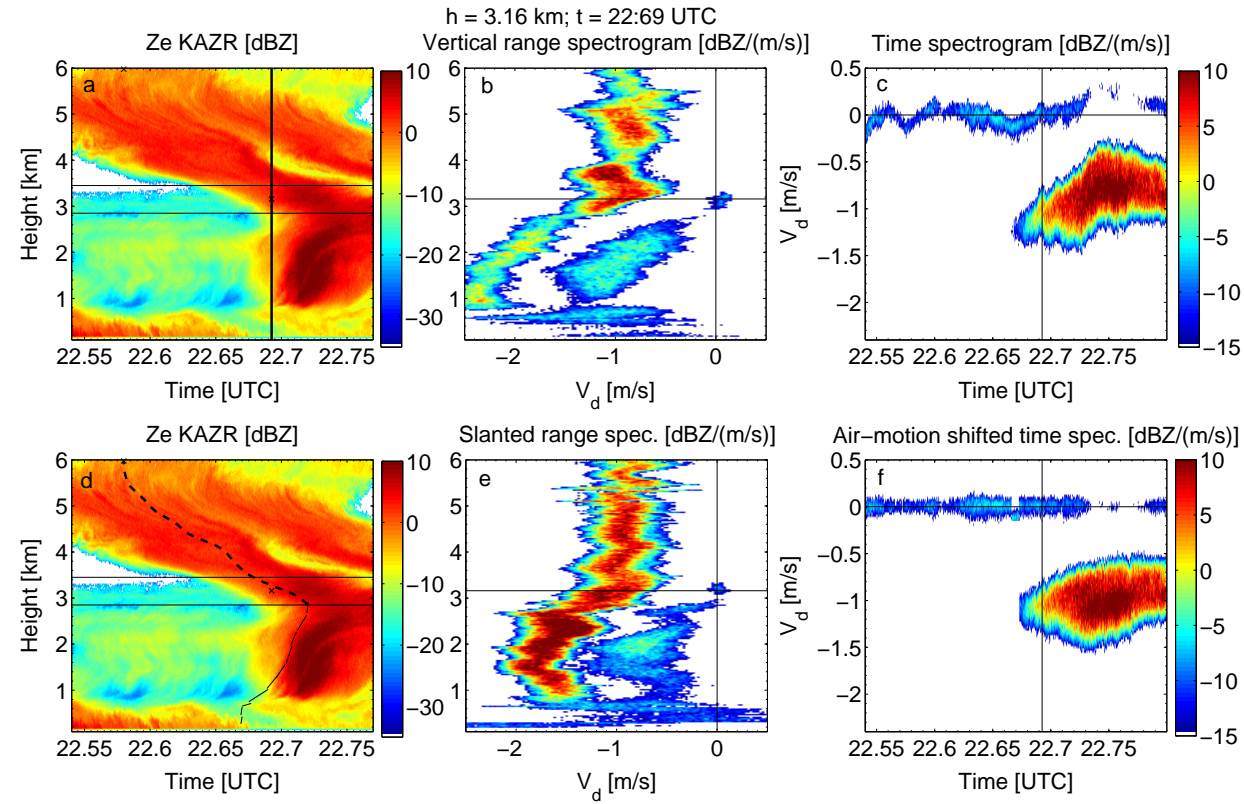

Figure 6. Panels (a, d) show KAZR reflectivity (Ze) field. There, the location of the SLW layer is indicated by thin horizontal black lines. The upper middle and upper right panels show range and time spectrograms of vertical profile which is indicated by a black vertical line in (a); the lower middle and lower right panels along slanted fall streak are shown in (d) as a dashed line. Panel (b) shows vertical range spectrogram along vertical black line in upper left panel, (c) time spectrogram at $3.16 \mathrm{~km}$, (e) slanted range spectrogram along dashed line in (d). Panel (f) shows the air-motion-corrected time spectrogram at $3.16 \mathrm{~km}$.

Based on the liquid peak reflectivity (Fig. 5c) of the SLW layer at $2.9-3.4 \mathrm{~km}$ the mean liquid water path of this layer (averaged between the two slanted paths in Fig. 5) was estimated to be $80-90 \mathrm{~g} \mathrm{~m}^{-2}$.

\subsubsection{Fall streak tracking}

When vertical wind shear is observed, the analysis of vertical profiles is not sufficient to correctly trace the paths of evolution of hydrometeor populations, as already stated in Marshall (1953). Instead, it is necessary to follow the falling hydrometeor populations along slanted fall streaks if we want to estimate their microphysical evolution from the particlegenerating level $\left(z_{\mathrm{gen}}\right)$ to height $z$. As illustrated in Hogan and Kew (2005), the slanted fall streak patterns can be simulated in the radar time-height observation space by taking the mean Doppler velocity $V_{\mathrm{d}}$ as average fall velocity of the particle population and using the horizontal wind profile $u(z)$, e.g., from radio soundings closest in time to account for advection:

$\mathrm{d} z / \mathrm{d} t_{\mathrm{rad}}=\left(V_{\mathrm{d}}(z) u\left(z_{\mathrm{gen}}\right)\right) /\left(u(z)-u\left(z_{\mathrm{gen}}\right)\right)$.

Here, $u\left(z_{\text {gen }}\right)$ is the horizontal wind velocity at the particlegenerating level $z_{\text {gen }}$ which is assumed to be close to cloud top $\left(z_{\mathrm{gen}}=6 \mathrm{~km}\right)$ and $t_{\mathrm{rad}}$ is the radar time ( $x$ axis in timeheight plots in vertically pointing mode). It is important to note that $t_{\mathrm{rad}}$ is usually different from the sedimentation time of the particle population and that fall streaks are not iden- tical to particle trajectories but are a result of overlapping trajectories as they are advected over the radar (Bohren and Fraser, 1992). As in Hogan and Kew (2005), we use the finite difference equivalent of Eq. (1) and work our way downward level-by-level considering the displacement at level $z$ in the determination of displacement at level $z-1$. We use this technique to determine a fall streak for each radar time step. Subsequently, all averaged profiles (means and standard deviations) are determined for the fall streaks spanned between the two black slanted fall streaks in Fig. 5. Our focus of interest will be the uppermost SLW layer at the height range $2.9-3.4 \mathrm{~km}$.

The closest radio sounding in time was launched at 23.2 UTC, approximately $45 \mathrm{~min}$ after the snow front was first observed with the KAZR. Ideally, horizontal wind profiles at the time of interest should be used; however, overall agreement of the slope of the black simulated fall streaks in Fig. 5 with the slope of the reflectivity features (above $2.9 \mathrm{~km}$ ) seems to confirm that the horizontal wind field did not change considerably within these $45 \mathrm{~min}$. Below $3 \mathrm{~km}$ the slope of the black simulated fall streaks does not fit well with the Ze feature, which is tilted in the opposite direction compared to the fall streak above. Additional fall streak simulations (depicted in blue in Fig. 5a) show that this backward tilted slope is well matched by simulations if we assume $z_{\text {gen }}=2.9-3 \mathrm{~km}$ and the mean Doppler velocity of the rimed snow mode in Eq. (1). The lower-level Ze feature thus corresponds to the fall streaks of those snow particles that ex- 

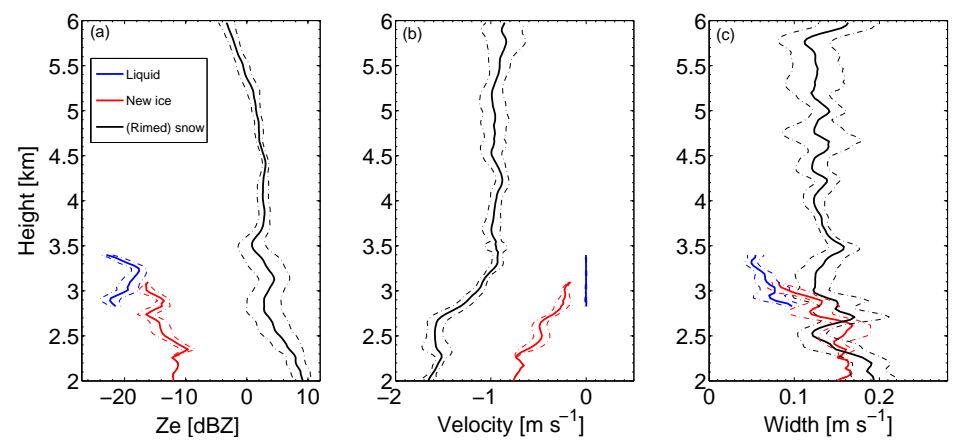

Figure 7. Slanted profile moments of SLW (blue), ice generated in the SLW layer (red), and frontal snow (black). Means and standard deviations of (a) reflectivity, (b) mean Doppler velocity, and (c) mode width are shown for the slanted paths encompassed by the two dashed lines in Fig. 5. Within the SLW layer, the velocities are corrected for vertical air motion.

perience riming in the SLW layer and indicates - as expected - the SLW layer as the correct generating level for the rimed particle population.

\subsubsection{Doppler spectrum evolution}

Figure 6 illustrates the necessity of tracking particle populations along slanted paths in conditions of wind shear by contrasting the KAZR Doppler spectrum evolution along the vertical line at 22.69 UTC in Fig. 6a versus along the estimated slanted fall streak in Fig. 6d. Clearly, the vertical range spectrogram in Fig. 6b shows some non-microphysical features - such as the discontinuity of spectral reflectivity at around $4 \mathrm{~km}$ - caused by taking a vertical profile when a slanted one is more representative. The range spectrogram along the slanted path in Fig. 6e tells a much more consistent microphysical evolution story of the particles when the frontal system moves in: above the $3.4 \mathrm{~km}$ height, snow with a mean Doppler velocity of around $1 \mathrm{~m} \mathrm{~s}^{-1}$ is observed. A few shallow layers of increased turbulence as well as thicker layers of up-/downdrafts result in a shift of the entire Doppler spectrum to more positive/negative values, respectively. At 2.9$3.4 \mathrm{~km}$, the layer of SLW with $V_{\mathrm{d}}$ fluctuating around $0 \mathrm{~m} \mathrm{~s}^{-1}$ is obvious in Fig. 6e as well as in the time spectrogram in Fig. 6c. Due to their small size, the terminal fall velocity of SLW droplets is negligible, so their $V_{\mathrm{d}}$ (also illustrated in Fig. 5d) can be used as an air motion tracer as done in previous studies (e.g., Shupe et al., 2004; Rambukkange et al., 2011). The $V_{\mathrm{d}}$ offset of the liquid mode from $0 \mathrm{~m} \mathrm{~s}^{-1}$ gives us an estimate of radar volume mean vertical air motion. Thus, in the SLW layer, the fall velocity of ice particles can be corrected for vertical air motion as illustrated in Fig. 6f. In Fig. 6e, the same air-motion correction is applied in regions with SLW. Again, the increase of $V_{\mathrm{d}}$ of the snow falling from higher layers into the SLW layers indicates riming. Also, the new ice mode generated in the SLW layer is revealed, as its $V_{\mathrm{d}}$ quickly increases from a few tens of $\mathrm{cm} \mathrm{s}^{-1}$ to $0.8 \mathrm{~m} \mathrm{~s}^{-1}$ between 2.8 and $2 \mathrm{~km}$.

\subsubsection{Profiles and probability density functions (PDFs) of radar moments}

Although the given observations cannot fully disentangle microphysical and dynamical effects, a fairly consistent picture of the evolution of the present hydrometeor populations can be formed (cf. Fig. 6). The means and standard deviations of $\mathrm{Ze}, V_{\mathrm{d}}$, and $\sigma$ of slanted profiles of the three hydrometeor populations (SLW, ice generated in the SLW layer, and frontal snow) are shown in Fig. 7. The average profile and standard deviations are based on all 110 simulated fall streaks encompassed by the two dashed lines in Fig. 5. Since in the Rayleigh scattering regime radar reflectivity is proportional to the number of particles $N$ and to $D^{6}$ (with $D$ being the diameter of the droplets), the reflectivity of the SLW droplets is very low ( -18 to $-22 \mathrm{dBZ}$ on average, cf. Fig. $7 \mathrm{a})$. The reflectivity of the ice generated in the SLW layer increases between 3.2 and $2 \mathrm{~km}$ from -16 to $-10 \mathrm{dBZ}$ because the ice particles grow due to water vapor deposition and aggregation. At the same time, the $V_{\mathrm{d}}$ of the ice mode increases from 0.2 to $0.7 \mathrm{~m} \mathrm{~s}^{-1}$ (cf. Fig. 7b). The absence of an air motion tracer outside of the SLW layer does not allow for vertical air motion contributions to the observed $V_{\mathrm{d}}$ to be accounted for. As a result, the observed $V_{\mathrm{d}}$ is not equal to the terminal fall velocity of the ice particles but could be higher (in updrafts) or lower (in downdrafts). Due to its large particles, the greatest contribution to the total radar return is of course given by the frontal snow mode. The total increase of mean $\mathrm{Ze}$ of this mode from 6 to $2 \mathrm{~km}$ is $12 \mathrm{dBZ}$; however, from $6 \mathrm{~km}$ to the top of the SLW layer, the mean increase of Ze and $V_{\mathrm{d}}$ of the snow mode is only moderate ( $5 \mathrm{dBZ}$ and $\left.0.15 \mathrm{~m} \mathrm{~s}^{-1}\right)$, suggesting only moderate growth of the snow particles, which is likely due to water vapor deposition in higher parts of the cloud. $V_{\mathrm{d}}$ of the frontal snow mode increases from 1 to $1.65 \mathrm{~m} \mathrm{~s}^{-1}$ between 3.2 and $2 \mathrm{~km}$. Spectrum width profiles in Fig. 7c show several thin turbulent layers in which the standard deviation of $\sigma$ is high. $\sigma$ of the SLW mode is smallest $\left(0.05-0.07 \mathrm{~m} \mathrm{~s}^{-1}\right)$ while $\sigma$ of the new ice and frontal snow mode are on the order of $0.1-0.2 \mathrm{~m} \mathrm{~s}^{-1}$. As previously men- 

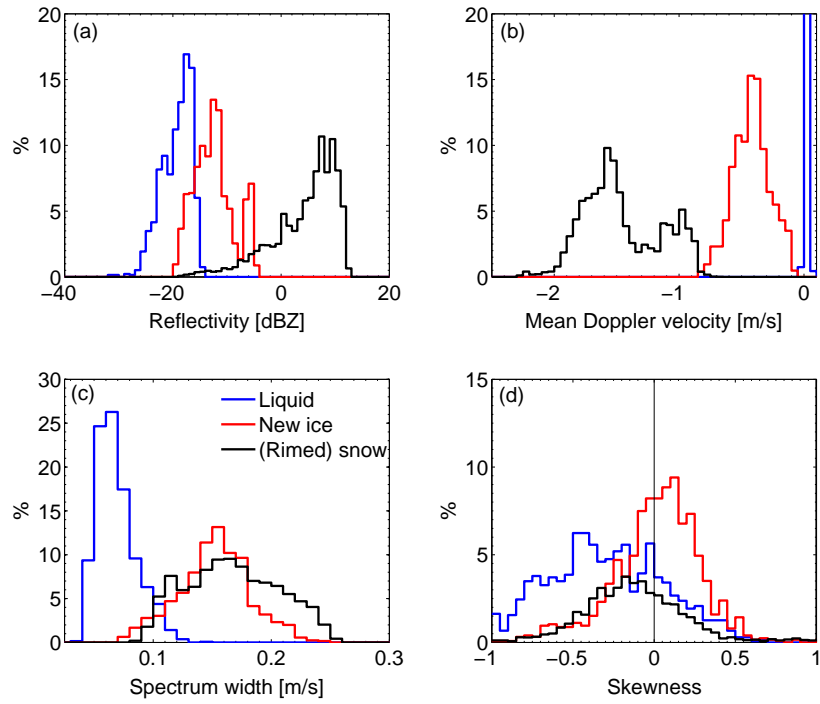

Figure 8. Probability density functions (PDFs) of noise-separated peaks of SLW (blue), ice generated in the SLW layer (red), and frontal snow (black) for the slanted paths encompassed by the two dashed lines in Fig. 4. Only data from surface to below top of the SLW layer $(3.4 \mathrm{~km})$ are considered. Please note that the PDF of SLW $V_{\mathrm{d}}$ is cut at $20 \%$.

tioned, larger $\sigma$ can be caused by a superposition of broad PSD and sub-volume turbulence.

Probability density functions (PDFs) of the moments of the three hydrometeor populations are shown in Fig. 8. Only data points from below the SLW layer top $(3.4 \mathrm{~km})$ down to the surface and between the two black dashed fall streaks in Fig. 5 are considered. For Ze and $V_{\mathrm{d}}$ there is very little overlap in the PDF of each hydrometeor population. In uniform beam-filling conditions and sub-volume turbulence, the Doppler spectrum of a cloud droplet PSD is symmetrical and near-Gaussian, resulting in zero skewness (Kollias et al., 2011). In contrast, the PDF of the observed SLW mode is skewed towards negative values, indicating the presence of supercooled drizzle at around $-12{ }^{\circ} \mathrm{C}$. The presence of drizzle is also indicated in Fig. 9 where the joint PDF of skewness and Ze is shown. While liquid-mode skewness fluctuates around zero for Ze below $-20 \mathrm{dBZ}$, it becomes increasingly negative at higher Ze values of -20 to $-16 \mathrm{dBZ}$. The existence of drizzle in SLW layers at the temperature range of -5 to $-12^{\circ} \mathrm{C}$ was also found by Verlinde et al. (2013) for Arctic multilayered mixed-phase clouds; the skewness-reflectivity signature as shown in Fig. 9 is qualitatively similar to the signatures observed in warm drizzle clouds (Luke and Kollias, 2013).

\subsection{1-D microphysical bin modeling}

The comprehensive observations were used as input to a onedimensional (1-D) bin microphysical model. The model is based on the warm rain model first presented in Szyrmer

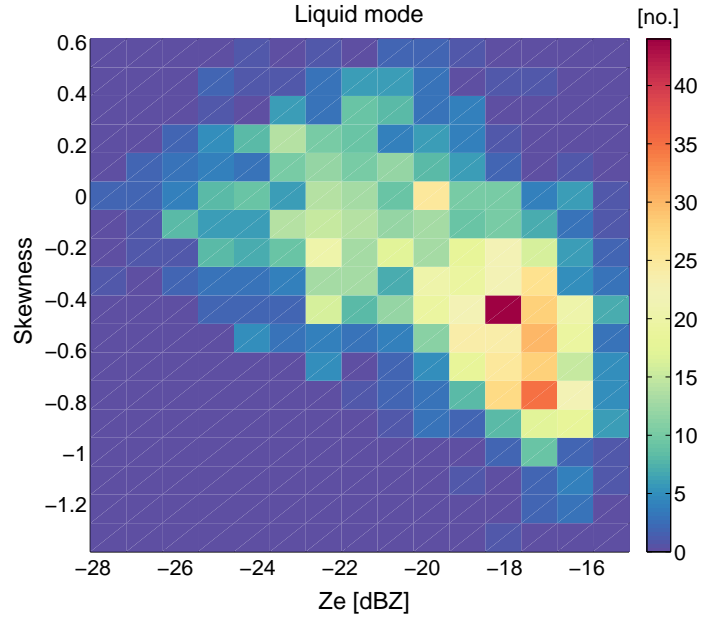

Figure 9. A joint PDF of frequency of occurrence (number of pixels) of skewness and reflectivity of supercooled liquid mode encompassed by the two black fall streaks in Fig. 5.

et al. (2005) and modified to include the ice processes of deposition, aggregation, and riming. The leading question is whether it is possible to reproduce the evolution of the observed radar moments of the rimed snow mode in the SLW layer using radar forward modeling of the microphysical model output. Forcing the model output to agree with the observations could help us to evaluate different proposed riming efficiency schemes that have been implemented as options in the model (see Appendix A). The microphysical modeling was limited to the SLW layer between 2.9 and $3.4 \mathrm{~km}$ and focused on the evolution of the moments ( $\mathrm{Ze}, V_{\mathrm{d}}$, $\sigma)$ of the frontal snow mode.

\subsubsection{Model description}

The 1-D steady-state model simulates the height evolution of the bin-resolved snow PSD introduced at the model's uppermost level (which in this study is the top of the SLW layer at $3.4 \mathrm{~km}$ ). The model input includes the vertical profiles of temperature, pressure, relative humidity (taken from the radio sounding, cf. Fig. 1) and vertical air motion (derived from the SLW-mode $V_{\mathrm{d}}$; cf. Fig. 10). The cloud droplet PSD at each level within the SLW layer is calculated from the liquid peak reflectivity profile, assuming that the cloud droplets follow a log-normal size distribution with a height-independent prescribed droplet number concentration $N$ and dispersion parameter $\sigma_{\mathrm{PSD}}\left(N=30 \mathrm{~cm}^{-3}, \sigma_{\mathrm{PSD}}=0.4\right)$ which are also taken for calculations of liquid water content (LWC) in Fig. 10.

The evolution of the snow mode along the fall streak is simulated by explicitly calculating the contribution to particle growth by the microphysical processes of water vapor diffusion, aggregation, and riming. In the model setup used in the presented simulations, the water vapor deposition and 

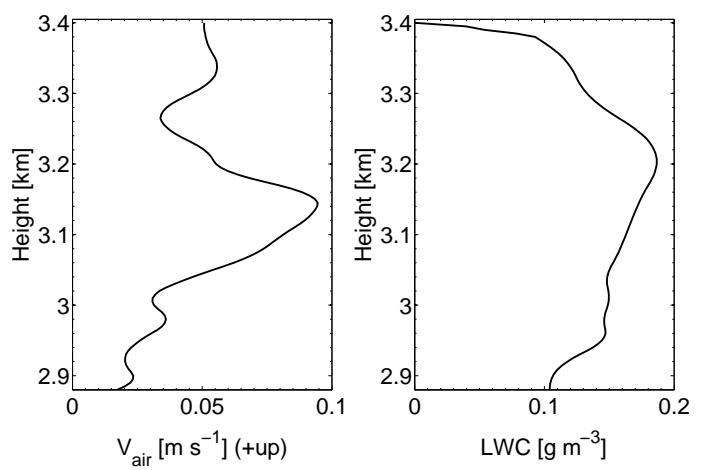

Figure 10. Mean vertical air motion profile ( $V_{\text {air }}$, left) derived from liquid-mode mean Doppler velocity and liquid water content (LWC, right) derived from liquid peak reflectivity between the two black fall streaks in Fig. 5, respectively.

aggregation processes conserve the area ratio, aspect ratio, and mass-size relationships. The deposition calculations use the results of Field et al. (2008) to describe the capacitance, except for the smaller particles for which the electrostatic capacitance approximation for thin plates is assumed, and the ventilation factor proposed by Hall and Pruppacher (1976) is adapted. The value of aggregation efficiency is set to 0.2. Details of the riming parameterizations are presented in Appendix A.

The frontal snow PSD is introduced at the uppermost model level in a functional form of a generalized gamma function with melted diameter representing particle size. The values of the two shape parameters are taken from Delanoë et al. (2005) for the form that is most consistent with the observations. The initial mass-size relation of a power law form with exponent 2 and prefactor $0.0012 \mathrm{~g} \mathrm{~cm}^{-2}$ is used. The rimed fraction of the snow particles at the model's uppermost level is set to 0 . The initial area ratio is calculated from the empirical relation between area ratio and particle density in Heymsfield et al. (2002) for side plane aggregates (particle density $=0.18$ area ratio $^{1.5}$ ).

\subsubsection{Comparison of model output and observations}

In Fig. 11, KAZR-observed profiles of snow-mode radar moments and the modeled moments are compared. Backscattering calculations are performed using Mie spheres with nonuniform mass distribution (Fabry and Szyrmer, 1999). The terminal velocity of snow particles - unrimed at the top and partially rimed below - is calculated based on the method proposed by Heymsfield and Westbrook (2010). However, two different possibilities for the evolution of the area ratio with riming are implemented. In the first approach (denoted by 1 in Fig. 11) for a given particle maximum diameter, the increase of the area ratio from the initial value is parameterized as a function of the aspect ratio modified by riming. In the second approach (denoted by 2 in Fig. 11) the increase of the area ratio is smaller and is obtained assuming that the initial relation between area ratio and particle density is maintained, i.e., the increase of the area ratio results from the increase of mass only.

In addition to the sensitivity of the terminal velocity of the rimed snow particles to the evolution of the area ratio relationship, the sensitivity of the modeled radar moments of the rimed snow mode to different riming efficiencies is evaluated. Specifically, in one model realization, the riming efficiency parameterizations from Hall (1980) and Cober and List (1993) for small and large ice particles are used, respectively. Model results using this particular parameterization are denoted as Hall Cober in Fig. 11. In another model realization, the riming efficiency parameterization proposed by Lohmann (2004), assuming plates for small D and aggregates for large $\mathrm{D}$ is adapted. Model results using this approach are denoted as Lohmann in Fig. 11.

Two effects can explain some of the discrepancies between the observed and modeled profiles. First, dynamical effects such as turbulence are not included in the radar forward model that estimates the radar Doppler spectrum width profile. Thus, the forward simulation cannot reproduce the spectrum broadening of the rimed mode below $3 \mathrm{~km}$ (cf. Fig. 11c). Second, there are uncertainties in the exact slope of the fall streaks due to the fact that the horizontal wind profile from the sounding is not taken at the time of interest but 45 min later. Overall, the evolution of the rimed snow-mode moments in the SLW layer can be reproduced by the model (within the standard deviations). In Fig. 11a, the observed and modeled Ze profile shows an increase from the top of the SLW layer to about $3.15 \mathrm{~km}$ which is attributed to an increase of mass of the snow when the liquid droplets attach to the snowflakes. Below $3.15 \mathrm{~km}$, the $\mathrm{dZe} / \mathrm{d} z$ is slightly reduced because even with the increase of mass, the increase of backscatter is very low and at the same time there is a reduction of particle number concentration. Except for the aforementioned influence of turbulence on spectrum width, the model reproduces the mean Doppler velocity and spectrum width profiles well. With the increase in mass and density during the riming process, particle fall velocities of the rimed snow steadily increase from top to bottom of the SLW layer from about 0.95 to $1.2 \mathrm{~m} \mathrm{~s}^{-1}$. The model is also capable of reproducing the small decrease in the spectrum width due to differences in the riming efficiency of small and large particles, leading to a small reduction in the spread of the rimed particles' fall velocities.

\section{Summary and conclusions}

For a frontal winter snowfall event observed at the SMEAR II site in Hyytiälä in Finland during the BAECC-SNEX field experiment in 2014, we show that by disentangling the contributions of the different hydrometeor populations to total vertically pointing cloud radar returns, it is possible to follow 

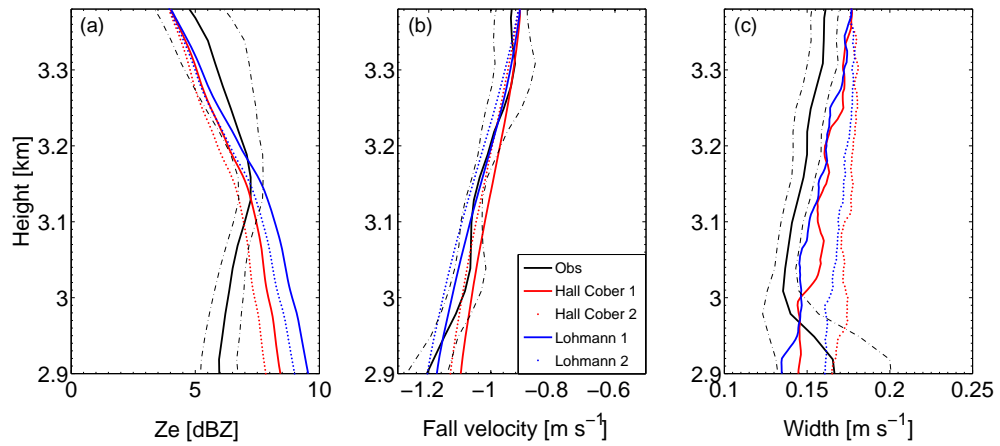

Figure 11. A comparison of observed and modeled moments of the frontal snow mode in the SLW layer. Black solid and dashed lines refer to the mean and standard deviation of the slanted paths encompassed by the two black fall streaks in Fig. 5. Model results based on riming efficiencies by Hall \& Cober as well as Lohmann are shown in red and blue, respectively (see text for details). Model results assuming area ratio increase with mass and rimed fraction (solid red and blue line) as well as with mass only (dotted red and blue) are shown.

the microphysical evolution of the present cloud and precipitation particles. For that purpose, we work with the entire radar Doppler spectrum instead of only considering cloud radar moments, which are integrated parameters of the spectrum.

The analysis presented here focuses on a band of snow that falls through a SLW layer, where it experiences riming and where new ice particle formation also takes place. A detailed analysis of the vertical evolution of radar moments of the frontal snow, SLW droplets, and freshly generated ice in terms of their evolution of radar moments $\left(\mathrm{Ze}, V_{\mathrm{d}}, \sigma\right)$ is presented.

The extensive analysis accounts for the vertical shear of the horizontal wind and the tracking of particle populations is performed along slanted paths instead of vertical profiles. Furthermore, the multiple noise-floor-separated modes of the radar Doppler spectra are analyzed and the moments of the SLW, ice, and rimed snow determined separately. From the $V_{\mathrm{d}}$ and Ze of the SLW droplets we estimate vertical air motion and LWC within the SLW layer, respectively.

The observations were used to set up and evaluate a 1-D steady-state bin microphysical model that accounts for the processes of deposition, aggregation, and riming. In particular, the profiles of vertical air motion and SLW content, along with thermodynamic variables from the nearest sounding were used to set up the steady-state conditions within the SLW layer. The radar moments at the top of the SLW layer were used to initiate the unrimed snow PSD. The radar Doppler spectrum analysis enabled isolation of the radar moments of the rimed snow within the SLW layer.

The microphysical model output (PSD of rimed snow particles) is used as input to a simple radar forward model that reproduces the three radar Doppler moments. The scattering model used to estimate the backscattering cross section of the snow particles is based on a two-layer spherical model introduced by Fabry and Szyrmer (1999). The uncertainties associated with this backscattering computation have been discussed in Szyrmer et al. (2012). While there are several different methods to prescribe the scattering calculations of snow particles (e.g., Tyynelä et al., 2013; Hogan and Westbrook, 2014), the height evolution of the radar moments of the rimed snow mode is not very sensitive to the scattering method used. Also, the very small particle sizes observed at the surface indicate that larger snowflakes which produce more complex Mie scattering, as for example seen later on 21 February 2014 (Kneifel et al., 2015), were not present during the period of interest.

Assuming a generalized gamma function with melted diameter representing particle size and using two different methods to estimate the terminal fall velocity of the rimed particles as well as two different methods to estimate the riming efficiency of the snow particles, we were able to reproduce the observed profiles (Fig. 11). Modeling was also performed, assuming an exponential snow PSD form (not shown). For this PSD form it is found that the modeled profiles of the rimed snow $\mathrm{Ze}$ and $V_{\mathrm{d}}$ are similar to those modeled using the generalized gamma function PSD. However, for the exponential PSD assumption, the modeled radar Doppler spectrum width profile had much less sensitivity to riming efficiency parameterization or choice of area ratio increase.

The case presented here was carefully selected to represent a scenario where riming is the dominant process that modulates the snow radar moments (riming fingerprinting). The simulations indicate that for fixed parameterizations for deposition and aggregation, the number of combinations of the riming and velocity parameterizations resulting in profiles that are comparable to the observations is rather limited. However, changing any of these factors may lead to different results. In other words, the effect of choosing different riming efficiency parameterizations is on the same order as choosing different options for area ratio increase, and thus also fall velocity calculations, as indicated by a equidistant spread of modeled profiles of Ze, and $V_{\mathrm{d}}$ in Fig. 11. 
Thus, no clear conclusions can be made as to which riming parameterization is more appropriate in this particular case due to large sensitivity of the model simulations to several factors other that those we assume, because of a lack of additional observational constraints. The profiling radar observations provide a height evolution perspective, which is a critical constraint for fingerprinting studies that aim to "isolate" a vertical layer where a particular microphysical process dominates particle growth. However, as it is evident from the sensitivity of the simulations, in situ observations giving exact velocity-size relations, particle size and density estimates, and information about particle shape are needed to further limit the choices in the model setup leading to true advancement in our understanding of riming and other ice microphysical processes. While extensive ground-based in situ data were gathered during BAECC-SNEX, the period of interest was characterized by low precipitation rates which hampered the ground-based microphysical retrievals. Furthermore, measurements of the LWC and ice PSD at the top of the SLW layer would have been key parameters to constrain the model runs. This points to the future need for coordinated (aircraft-based) in situ observations combined with profiling and scanning radar observations. The DOE ARM Program and the ARM Aerial Facility (AAF) are well positioned to conduct such targeted observational-modeling studies in the future.

The present riming case study was selected from the extensive BAECC campaign data set due to its nearly ideal situation in which the fall velocity separation of the different hydrometeor classes is strong enough to produce individual peaks separated by the mean noise floor in the cloud radar Doppler spectra. During other riming cases, cloud radar Doppler spectra multimodalities were observed; however, these peaks were usually merged. These cases are more complicated to disentangle, most likely due to a more complex mixture of dominant ice growth processes (water vapor deposition, aggregation, and riming) which all played an important role. Fingerprinting studies of one particular microphysical growth process - such as riming - requires more simple microphysical situations as we think is the case in the presented study.

In situations with merged broad peaks it is very challenging to define objective peak separation criteria and to thus disentangle the relative contributions of different hydrometeor populations to the total radar returns. In a previous mixed-phase cloud radar Doppler spectra study (Shupe et al., 2004) empirical "peak-picking" criteria were developed by manual inspection of the peak-picking results. There, it was emphasized that the criteria depend on the observed mixedphase cloud cases and cloud radar sampling parameters (such as temporal resolution and number of fast Fourier transform points). The development of robust cloud radar Doppler spectra peak separation criteria in mixed-phase clouds is the topic of future studies; the data set gathered during the BAECC campaign offers great potential for such studies.

\section{Data availability}

All data used in this study are publicly accessible at the ARM data archive: www.archive.arm.gov. 


\section{Appendix A: Parameterizations of riming efficiency and physics}

The increase in mass of an individual snow particle via the riming process is calculated with the stochastic collection equation. Different options for the calculations of the riming efficiency, the evolution of area ratio and aspect ratio via the riming process, and the related increase in particle fall velocity are included in the model. Sizedependent riming efficiency parameterizations proposed in the literature and introduced in the model can be separated into two groups. The first group describes the efficiency of smaller pristine crystals, mainly at the first stage of riming, based on numerical simulations of Pitter and Pruppacher (1974), Pitter (1977), and Wang and Ji (2000), and proposed by Hall (1980), Young (1993), Geresdi (1998), and Lohman (2004) taken from Mitchell (1990). The second group of parameterizations introduced in the model are more suitable for larger more spherical particles; the parameterization developed for the accretional growth of raindrops (Beard and Grover, 1974), a parameterization derived for graupel (Cober and List, 1993), and the one proposed by Lohmann (2004) for aggregates based on the experimental results of Lew et al. (1986) are included. Some examples of the dependence of the riming efficiency on the snow particle size calculated for different cloud droplet diameters are shown in the supporting information of Leinonen and Szyrmer (2015).
Different approaches to describing the physics of riming result in different descriptions of the changes of the properties of particles undergoing riming growth. Aggregates and branched particles appear to grow by "filling in", resulting in an increase of particle effective density while the major dimension does not change. Mainly, the minor dimension is expected to increase; but when the particle effective density is large enough, associated with a quasi-spherical shape, the filling process has to be replaced by an increase of both dimensions with the aspect ratio maintained (e.g., Morrison and Grabowski, 2010). Different options of change of particle aspect ratio accompanying the growth by riming in the model use the rime density calculated from empirical formulas (Macklin, 1962; Pflaum and Pruppacher, 1979; Heymsfield and Pflaum, 1985). The following options for the evolution of the area ratio for a given increase of the rimed fraction can be selected in the model: (i) using one of the empirical relations of mass-density-area ratio (by choosing an appropriate relation from the table in Szyrmer et al., 2012 or others), or (ii) obtained by interpolation based on rimed fraction between the values associated with the unrimed particle and graupel (as in Lin and Colle, 2011), or (iii) calculated from the assumed relation of particle geometry between area ratio and aspect ratio (e.g., Avramov et al., 2011; Jensen and Harrington, 2015). 
Acknowledgements. The authors thank the entire BAECC-SNEX science team, the AMF2 team, and the SMEAR II staff for data acquisition and analysis, as well as Dimitri Moisseev for discussion of in situ observational results. The Department of Energy (DOE) Atmospheric System Research (ASR) program provided funding to conduct this research through the ASR radar science grant. Heike Kalesse conducted this work within the framework of the DFG project COMPoSE, GZ: KA 4162/1-1. Work contributed by Stefan Kneifel was also supported by a PostDoc fellowship from the German Academic Exchange Service (DAAD).

Edited by: T. Petäjä

\section{References}

Avramov, A., Ackerman, A. S., Fridlind, A. M., van Diedenhoven, B., Botta, G., Aydin, K., Verlinde, J., Korolev, A. V., Strapp, J. W., McFarquhar, G. M., Jackson, R., Brooks, S. D., Glen, A., and Wolde, M.: Toward ice formation closure in Arctic mixedphase boundary layer clouds during ISDAC, J. Geophys. Res., 116, D00T08, doi:10.1029/2011JD015910, 2011.

Barrett, A., Hogan, R., and Forbes, R.: Improving mixed-phase cloud representation in weather and climate models, Poster contribution at AMS Clouds and Radiation Conference, Portland, OR, 2010

Baschek, B., Schefold, R., and Barthazy, E.: How do updrafts and embedded convection influence riming?, Proceedings of ERAD, 261-267, 2004.

Beard, K. V. and Grover, S. N.: Numerical collision efficiencies for small raindrops colliding with micron size particles, J. Atmos. Sci., 31, 543-550, 1974.

Bohren, C. F. and Fraser, A. B.: Fall streaks: Parabolic trajectories with a twist, Am. J. Phys., 60, 1030, doi:10.1119/1.16982, 1992.

Borys, R. D., Lowenthal, D. H., Cohn, S. A., and Brown, W. O. J.: Mountaintop and radar measurements of anthropogenic aerosol effects on snow growth and snowfall rate, Geophys. Res. Lett., 30, 1538, doi:10.1029/2002GL016855, 2003.

Cadeddu, M. P., Liljegren, J. C., and Turner, D. D.: The Atmospheric radiation measurement (ARM) program network of microwave radiometers: instrumentation, data, and retrievals, Atmos. Meas. Tech., 6, 2359-2372, doi:10.5194/amt-6-2359-2013, 2013.

Cantrell, W. and Heymsfield, A.: Production of Ice in Tropospheric Clouds, B. Am. Meteorol. Soc., 86, 795-807, 2005.

Cober, S. and List, R.: Measurements of the Heat and Mass Transfer Parameters Characterizing Conical Graupel Growth, J. Atmos. Sci., 50, 1591-1609, 1993.

Delanoë, J., Protat, A., Testud, J., Bouniol, D., Heymsfield, A. J., Bansemer, A., Brown, P. R. A., and Forbes, R. M.: Statistical properties of the normalized ice particle size distribution, J. Geophys. Res., 110, D10201, doi:10.1029/2004JD005405, 2005.

Fabry, F. and Szyrmer, W.: Modeling of the melting layer. Part II: Electromagnetics, J. Atmos. Sci., 56, 3593-3600, 1999.

Field, P. R., Heymsfield, A. J., Bansemer, A., and Twohy, C. H.: Determination of the combined ventilation factor and capacitance for ice crystal aggregates from airborne observations in a tropical anvil cloud, J. Atmos. Sci., 65, 376-391, 2008.
Geresdi, I.: Idealized simulation of the Colorado hailstorm case: Comparison of bulk and detailed microphysics, Atmos. Res., 45, 237-252, doi:10.1016/S0169-8095(97)00079-3, 1998.

Gregory, D. and Morris, D.: The sensitivity of climate simulations to the specification of mixed phase clouds, Clim. Dynam., 12, 641-651, 1996.

Hall, W. D.: A Detailed Microphysical Model Within a TwoDimensional Dynamic Framework: Model Description and Preliminary Results, J. Atmos. Sci., 37, 2486-2507, 1980.

Hall, W. D. and Pruppacher, H. R.: The survival of ice particles falling from cirrus clouds in subsaturated air, J. Atmos. Sci., 33, 1995-2006, 1976.

Hari, P. and Kulmala, M.: Station for Measuring EcosystemAtmosphere Relations (SMEAR II), Boreal Environ. Res., 10, 315-322, 2005.

Heymsfield, A. and Pflaum, J.: A quantitative assessment of the accuracy of techniques for calculating graupel growth, J. Atmos. Sci., 42, 2264-2274, 1985.

Heymsfield, A. and Westbrook, C.: Advances in the estimation of ice particle fall speeds using laboratory and field measurements, J. Atmos. Sci., 67, 2469-2482, 2010.

Heymsfield, A., Lewis, S., Bansemer, A., Iaquinta, J., Miloshevich, L. M., Kajikawa, M., Twohy, C., and Poellot, M. R.: A general approach for deriving the properties of cirrus and stratiform ice cloud particles, J. Atmos. Sci., 59, 3-29, doi:10.1175/15200469(2002)059<0003:AGAFDT>2.0.CO;2, 2002.

Hildebrand, P. and Sekhon, R.: Objective Determination of the Noise Level in Doppler Spectra, J. Appl. Meteorol., 13, 808-811, 1974.

Hogan, R. J. and Kew, S. F.: A 3D stochastic cloud model for investigating the radiative properties of inhomogeneous cirrus clouds, Q. J. Roy. Meteor. Soc., 131, 2585-2608, doi:10.1256/qj.04.144, 2005.

Hogan, R. J. and Westbrook, C. D.: Equation for the Microwave Backscatter Cross Section of Aggregate Snowflakes Using the Self-Similar Rayleigh-Gans Approximation, J. Atmos. Sci., 71, 3292-3301, doi:10.1175/JAS-D-13-0347.1, 2014.

Illingworth, A. J., Hogan, R. J., O'Connor, E. J., Bouniol, D., Brooks, M. E., Delanoë, J., Donovan, D. P., Eastment, J. D., Gaussiat, N., Goddard, J. W. F., Haeffelin, M. and Baltink, H. K., Krasnov, O. A., Pelon, J., Piriou, J.-M., Protat, A., Russchenberg, H. W. J., Seifert, A., Tompkins, A. M., van Zadelhoff, G.-J., Vinit, F., Willén, U., Wilson, D. R., and Wrench, C. L.: CLOUDNET: Continuous Evaluation of Cloud Profiles in Seven Operational Models Using Ground-Based Observations, B. Am. Meteorol. Soc., 88, 883-898, doi:10.1175/BAMS-88-6-883, 2007.

Jensen, A. and Harrington, J.: Modeling ice crystal aspect ratio evolution during riming: A single-particle growth model, J. Atmos. Sci., 72, 2569-2590, doi:10.1175/JAS-D-14-0297.1, 2015.

Kanitz, T., Seifert, P., Ansmann, A., Engelmann, R., Althausen, D., Casiccia, C., and Rohwer, E. G.: Contrasting the impact of aerosols at northern and southern midlatitudes on heterogeneous ice formation, Geophys. Res. Lett., 38, L17802, 2011.

Klein, S. A., Zhang, Y., Zelinka, M. D., Pincus, R., Boyle, J., and Gleckler, P. J.: Are climate model simulations of clouds improving? An evaluation using the ISCCP simulator, J. Geophys. Res., 118, 1329-1342, 2013.

Kneifel, S., Lerber, A., Tiira, J., Moisseev, D., Kollias, P., and Leinonen, J.: Observed relations between snowfall microphysics 
and triple-frequency radar measurements, J. Geophys. Res.Atmos., 120, 6034-6055, doi:10.1002/2015JD023156, 2015.

Kollias, P., Albrecht, B. A., Lhermitte, R., and Savtchenko, A.: Radar observations of updrafts, downdrafts, and turbulence in fair-weather cumuli, J. Atmos. Sci., 58, 1750-1766, 2001.

Kollias, P., Clothiaux, E. E., Miller, M. A., Albrecht, B. A., Stephens, G. L., and Ackerman, T. P.: Millimeter-wavelength radars - New frontier in atmospheric cloud and precipitation research, B. Am. Meteorol. Soc., 88, 1608-1624, 2007 a.

Kollias, P., Miller, M. A., Luke, E. P., Johnson, K. L., Clothiaux, E. E., Moran, K. P., Widener, K. B., and Albrecht, B. A.: The Atmospheric Radiation Measurement Program cloud profiling radars: Second-generation sampling strategies, processing and cloud data products, J. Atmos. Ocean Tech., 24, 1199-1214, 2007b.

Kollias, P., Remillard, J., Luke, E., and Szyrmer, W.: Cloud radar Doppler spectra in drizzling stratiform clouds: 1 . Forward modeling and remote sensing applications, J. Geophys. Res., 116, D13201, doi:10.1029/2010JD015237, 2011.

Kollias, P., Bharadwaj, N., Widener, K., Jo, I., and Johnson, K.: Scanning ARM Cloud Radars. Part I: Operational Sampling Strategies, J. Atmos. Ocean. Tech., 31, 569-582, 2014.

Lebo, Z. J., Johnson, N. C., and Harrington, J. Y.: Radiative influences on ice crystal and droplet growth within mixed-phase stratus clouds, J. Geophys. Res., 113, D09203, doi:10.1029/2007JD009262, 2008.

Leinonen, J. and Szyrmer, W.: Radar signatures of snowflake riming: a modeling study, Earth Space Sci., 2, 346-358, doi:10.1002/2015EA000102, 2015.

Lew, J. K., Montague, D. C., Pruppacher, H. R., and Rasmussen, R. M.: A wind tunnel investigation on the riming of snowflakes. Part II: Natural and synthetic aggregates, J. Atmos. Sci., 43, 2410-2417, doi:10.1175/15200469(1986)043<2410:AWTIOT>2.0.CO;2, 1986.

Lin, Y. and Colle, B.: A new bulk microphysical scheme that includes riming intensity and temperature-dependent ice characteristics, Mon. Weather Rev., 139, 1013-1035, 2011.

Lloyd, G., Choularton, T. W., Bower, K. N., Crosier, J., Jones, H., Dorsey, J. R., Gallagher, M. W., Connolly, P., Kirchgaessner, A. C. R., and Lachlan-Cope, T.: Observations and comparisons of cloud microphysical properties in spring and summertime Arctic stratocumulus clouds during the ACCACIA campaign, Atmos. Chem. Phys., 15, 3719-3737, doi:10.5194/acp-15-37192015, 2015.

Lohmann, U.: Can Anthropogenic Aerosols Decrease the Snowfall Rate, J. Atmos. Sci., 61, 2457-2468, 2004.

Luke, E. and Kollias, P.: Separating Cloud and Drizzle Radar Moments during Precipitation Onset Using Doppler Spectra, J. Atmos. Ocean. Tech., 26, 167-179, 1656-1671, doi:10.1175/JTECH-D-11-00195.1, 2013.

Luke, E. P., Kollias, P., and Shupe, M. D.: Detection of supercooled liquid in mixed-phase clouds using radar Doppler spectra, J. Geophys. Res., 115, D19201, doi:10.1029/2009JD012884, 2010.

Macklin, W. C.: The density and structure of ice formed by accretion, Q. J. Roy. Meteor. Soc., 88, 30-50, 1962.

Marshall, J. S.: Precipitation trajectories and patterns, J. Meteorol., 10, 25-29, doi:10.1175/15200469(1953)010<0025:PTAP>2.0.CO;2, 1953.
Mitchell, D. L.: Evolution of snow-size spectra predicted by the growth processes of diffusion, aggregation and riming, Preprints, Conf. on Cloud Physics, San Francisco, CA, Am. Meteorol. Soc., 270-277, 1990.

Morrison, H. and Grabowski, W. W.: An Improved Representation of Rimed Snow and Conversion to Graupel in a Multicomponent Bin Microphysics Scheme, J. Atmos. Sci., 67, 1337-1360, doi:10.1175/2010JAS3250.1, 2010.

Morrison, H., de Boer, G., Feingold, G., Harrington, J., Shupe, M. D., and Sulia, K.: Resilience of persistent Arctic mixed-phase clouds, Nat. Geosci., 5, 11-17, 2012.

Mosimann, L.: An improved method for determining the degree of snow crystal riming by vertical Doppler radar, Atmos. Res., 37, 305-323, 1995.

Newman, A. J., Kucera, P. A., and Bliven, L. F.: Presenting the Snowflake Video Imager (SVI), J. Atmos. Ocean. Tech., 26, 167179, 2009.

Petäjä, T., O’Connor, E. J., Moisseev, D., Sinclair, V. A., Manninen, A. J., Väänänen, R., von Lerber, A., Thornton, J. A., Nicoll, K., Petersen, W., Chandrasekar, V., Smith, J. N., Winkler, P. M., Kröger, O., Hakola, H., Timonen, H., Brus, D., Laurila, T., Asmi, E., Riekkola, M.-L., Mona, L., Massoli, P., Engelmann, R., Komppula, M., Wang, J., Kuang, C., Bäck, J., Virtanen, A., Levula, J., Ritsche, M., and Hickmon, N.: BAECC, A field campaign to elucidate the impact of Biogenic Aerosols on Clouds and Climate, B. Am. Meteorol. Soc., doi:10.1175/BAMS-D-1400199.1, online first, 2016.

Pflaum, J. C. and Pruppacher, H. R.: A wind tunnel investigation of the growth of graupel initiated from frozen drops, J. Atmos. Sci. 36, 680-689, 1979.

Pitter, R. L.: A reexamination of riming on thin ice plates, J. Atmos. Sci., 34, 684-685, doi:10.1175/15200469(1977)034<0684:AROROT>2.0.CO;2, 1977.

Pitter, R. L. and Pruppacher, H. R.: A numerical investigation of collision efficiencies of simple ice plates colliding with supercooled water drops, J. Atmos. Sci., 31, 551-559, doi:10.1175/15200469(1974)031<0551:ANIOCE>2.0.CO;2, 1974.

Pruppacher, H. and Klett, J.: Microphysics of Clouds and Precipitation, Kluwer Academic, 954 pp., Dordrecht, the Netherlands, 1997.

Rambukkange, P., Verlinde, J., Eloranta, E., Flynn, C., and Clothiaux, E.: Using Doppler Spectra to Separate Hydrometeor Populations and Analyze Ice Precipitation in Multilayered MixedPhase Clouds, IEEE Geosci. Remote Sens. Lett., 8, 108-112, doi:10.1109/LGRS.2010.2052781, 2011.

Shupe, M., Kollias, P., Matrosov, S., and Schneider, T.: Deriving mixed-phase cloud properties from Doppler radar spectra, J. Atmos. Ocean. Tech., 21, 660-670, 2004.

Shupe, M., Daniel, J. S., de Boer, G., Eloranta, E. W., Kollias, P., Luke, E. P., Long, C. N., Turner, D. D., and Verlinde, J.: A Focus On Mixed-Phase Clouds, B. Am. Meteorol. Soc., 89, 1549-1562, 2008.

Szyrmer, W., Laroche, S., and Zawadzki, I.: A microphysical bulk formulation based on scaling normalization of the particle size distribution. Part I: Description, J. Atmos. Sci., 62, 4206-4221, 2005.

Szyrmer, W., Tatarevic, A., and Kollias, P.: Ice clouds microphysical retrieval using 94-GHz Doppler radar observations: Basic 
relations within the retrieval framework, J. Geophys. Res., 117, D14203, doi:10.1029/2011JD016675, 2012.

Tyynelä, J., Leinonen, J., Westbrook, C. D., Moisseev, D., and Nousiainen, T.: Applicability of the rayleigh-gans approximation for scattering by snow flakes at microwave frequencies in vertical incidence, J. Geophys. Res., 118, 1826-1839, doi:10.1002/jgrd.50167, 2013.

Verlinde, J., Rambukkange, M. P., Clothiaux, E. E., McFarquhar, G. M., and Eloranta, E. W.: Arctic multilayered, mixedphase cloud processes revealed in millimeter-wave cloud radar Doppler spectra, J. Geophys. Res.-Atmos., 118, 13199-13213, doi:10.1002/2013JD020183, 2013.

Wang, P. K. and Ji, W.: Collision efficiencies of ice crystals at lowintermediate Reynolds numbers colliding with supercool cloud droplets: A numerical study, J. Atmos. Sci., 57, 1001-1009, 2000.

Weiss, R. R. and Hobbs, P. V.: The use of vertically pointing Doppler radar in cloud physics and weather modification studies, J. Appl. Meteorol., 14, 222-231, 1975.
Young, K. C.: Microphysical processes in clouds, Oxford University Press, 427 pp., 1993.

Yu, G., Verlinde, J., Clothiaux, E. E., and Chen, Y.-S.: Mixed-phase cloud phase partitioning using millimeter wavelength cloud radar Doppler velocity spectra, J. Geophys. Res.-Atmos., 119, 75567576, doi:10.1002/2013JD021182, 2014.

Zhang, D., Wang, Z., and Liu, D.: A global view of midlevel liquidlayer topped stratiform cloud distribution and phase partition from CALIPSO and CloudSat measurements, J. Geophys. Res., 115, D00H13, doi:10.1029/2009JD012143, 2010.

Zhang, D., Wang, Z., Heymsfield, A., Fan, J., and Luo, T.: Ice concentration retrieval in stratiform mixed-phase clouds using cloud radar reflectivity measurements and 1-D ice growth model simulations, J. Atmos. Sci., 71, 3613-3635, 2014. 